\title{
Efficacy in degradation of carcinogenic pollutant sulforhodamine $B$ by green synthesized silver nanoparticles
}

\author{
Ramakrishnan Jayakrishnan ${ }^{1 *} \mathbb{D}$, Anju Joseph ${ }^{2}$ and Vinoy Thomas ${ }^{2}$
}

\begin{abstract}
Colloidal Silver nano-particles were grown at room temperature using leaf extract of Ocimum tenuiflorum. The silver nanoparticles suspended in the solution were found to be stable for over a period of 2 months. Structural, optical and photo catalytic behavior of the suspended silver (Ag) nano-particles (NPs) was characterized. From TEM analysis the size of the silver nanoparticles was estimated to be $25-30 \mathrm{~nm}$. Our findings suggest that the ratio between the molarity of $\mathrm{AgNO} 3$ and the volume of leaf extract does not have any role in controlling the size of the Ag nano-particles. These green synthesized Ag nano-particles exhibit degradation of the carcinogenic organic pollutant sulforhodamine $B$ in absence of light.
\end{abstract}

Keywords: Nano-fluids, Ag Nano-particles, Photo-catalysis

\section{Introduction}

The emergence of nanotechnology and nano-medicine has opened an arena for research on bio-compactible materials with therapeutic potential. Silver is widely used in anti-microbial medicines, and in anti-biotic coatings on surgical equipment [1]. Silver exhibits the highest thermal and electrical conductivity among all known metals. Biological activity of silver has been attributed to the $\mathrm{Ag}^{+}$ion [2]. The advancements in the field of nano-science resulted in development of Silver nanoparticles (Ag-NPs) which exhibit unique physical and chemical properties [3]. The chemical stability, ability to exhibit localized surface plasma resonance, photo-catalytic activity and high conductivity resulted in renewed research interest on this material [3-5]. With the advent of new research tools and techniques Ag-NPs have demonstrated their applications in opto-electronic devices, food industry, cosmetics and antifungal effects and have

\footnotetext{
*Correspondence: rjk@keralauniversity.ac.in

1 Photovoltaic Research Laboratory, Department of Physics, University

of Kerala, Karyavattom P.O, Thiruvananthapuram, India

Full list of author information is available at the end of the article
}

eventually improved the tumor-killing properties of anticancer drugs [6-9].

Compared to physical and chemical methods that are trending the green route stands at advantage in being less dependent on requirements of solvents, capping agents and reducing agents [10-12]. Ocimum tenuiflorum also called the "Queen of the Herbs" is widely used in Indian Ayurveda for its diverse healing properties [11]. The leaves of Ocimum tenuiflorum contain a diversity of ingredients that have biological activity, including saponins, flavonoids, triterpenoids, and tannins [10-12]. It is well established that the biological activity of AgNPs is governed by factors like surface chemistry, size, size distribution, shape, particle morphology, particle composition, coating/capping, agglomeration and the type of reducing agents used for the synthesis of AgNPs [13-15]. The use of Ocimum tenuiflorum leaf extract for the production of Ag-NPs has not been reconnoitered extensively $[16,17]$. The use of the medicinal plant extract also opens up the possibility of synthesizing bio-compactible Ag-NPs that may find diverse applications [18-20].

Sulforhodamine B is a carcinogenic dye which is used by scientists as a classical aromatic pollutant to study 
non-enzymatic oxidative degradation as well as adsorption in waste water [21-24]. In this paper, we report on the efficacy of the biosynthetic resource-Ocimum tenuiflorum extract for the bio-reduction of silver metal to silver nano-particles and their efficacy in catalytic degradation of the pollutants sulforhodamine B. This investigation may provide basis for the understanding of mechanism of use of Ocimum tenuiflorum extract for synthesis of nanostructures and use of these nano-structures for pollutant removal from industrial waste water [25].

\section{Materials and methods}

\section{Synthesis of silver nano suspension}

Fresh leaves of Ocimum tenuiflorum were weighed to $0.205 \mathrm{~g}$, and thoroughly washed in distilled water to remove any fungal or dust residuals. They were then finely chopped and mixed in $100 \mathrm{ml}$ of distilled water which was boiled for $1 \mathrm{~h}$. The liquid extract was collected by filtering the cooled mixture using filter paper. To study the effect of the volume of the leaf extract on the size and stability of Ag nano-particles, the molarity of $\mathrm{AgNO}_{3}$ was kept constant at $1 \mathrm{mM}$ and the nano-fluid suspension was prepared in three different ratios by varying the volume of leaf extract. In effect the molar ratio of leaf extract to $\mathrm{AgNO}_{3}$ was fixed as 1:1, 1:5 and 1:8. Nano-fluids so synthesized were labeled as 1S1, 1S5 and 1S8 respectively. Another set of samples in the 1:1 and 1:5 ratio were also prepared where the molarity of the leaf extract was kept constant at $3 \mathrm{mM}$. The nano-fluids so synthesized were labeled as $3 \mathrm{~S} 1$ and 3S5.Using these nano-fluids the effect leaf extract and molarity of $\mathrm{AgNO}_{3}$ on the size and stability of the suspended Ag nano-particle was studied. Other than the $\mathrm{AgNO}_{3}$ precursor solution only the leaf extract was used for growth of Nano-particles by us signifying the biosynthetic route optimized herein. No other synthetic chemicals or compounds were used for process optimization.

\section{Characterization of nano-particles}

Structural characterization was conducted using X-ray diffraction analysis. Selective area electron diffraction pattern was used to characterize the crystal structure of the synthesized Ag nano-particles. Transmission Electron Microscopy (TEM) was used to determine the size and shape of the nano-particles. Optical absorption studies of the synthesized nano-fluids was conducted to confirm the formation of silver nano-particles using UV-VIS spectrophotometer (UV 1800 Shimadzu) in the wavelength region of $400-800 \mathrm{~nm}$. To quantify the concentration of the synthesized Ag nano-particles inductively coupled mass spectrometry (ICP-MS) analysis was conducted using Thermo Fischer Scientific iCAP
RQ instrument. FTIR measurements were carried out to identify the possible biomolecules responsible for capping and efficient stabilization of the Ag nanoparticles synthesized by the Ocimum tenuiflorum leaf extract. The colloidal Ag NP solution was diluted in potassium bromide (in the ratio 1:50) and the FT-IR instrument was operated in diffuse reflectance mode (DRS-800). Spectra were collected from 400 to $4000 \mathrm{~cm}^{-1}$ at a resolution of $4 \mathrm{~cm}^{-1}$. Functional groups were identified using reference spectra.

\section{Photo-catalytic degradation of Rhodamine dye}

The photo-catalytic activities of the synthesized nanoparticles were studied by the photo-degradation of RhB dye in an aqueous solution under direct sunlight. In each experiment $2.5 \mathrm{ml}$ of the prepared nano-particle suspension was mixed with $15 \mathrm{ml}$ of Rhodamine dye of $20 \mu \mathrm{mol} / \mathrm{L}$ and kept under direct sunlight. Optical absorption studies of the mixture were carried out at regular intervals of time to study the degradation of the dye.

To measure the rate constants of the photo-catalytic degradation reaction $\mathrm{RhB}$ of different molarities of $5 \mu \mathrm{mol} / \mathrm{L}, 10 \mu \mathrm{mol} / \mathrm{L}, 15 \mu \mathrm{mol} / \mathrm{L}, 20 \mu \mathrm{mol} / \mathrm{L}, 25 \mu \mathrm{mol} / \mathrm{L}$, $30 \mu \mathrm{mol} / \mathrm{L}$ and $40 \mu \mathrm{mol} / \mathrm{L}$ were prepared and their degradation under direct solar irradiation was also studied. For this Ag nano-particles which had exhibited maximum degradation efficiency in the previous study were used. The degradation studies were carried out under direct sunlight irradiation (Chengannur: $9.3183^{\circ} \mathrm{N}, 76.611^{\circ} \mathrm{E}$; March 2019).

\section{Result and discussion XRD studies}

Figure 1 represents the X-ray diffraction spectrum for a thin film grown by drop cast technique using the sample 1S5. The planes (111), (202), (311) and (331) could be indexed from the data corresponding to the diffraction peaks at $2 \theta=38.9^{\circ}, 66.3^{\circ}, 79.2^{\circ}$ and $81.7^{\circ}$ respectively. The peaks were identified using the JCPDS file No. 04-0783, corresponding to the face centered cubic crystal structure.

\section{TEM analysis of sample 1S5}

The nano-fluid sample 1S5 which showed the highest stability and efficiency in dye degradation was subjected to TEM analysis to understand the structure and morphology of the formed Ag nano-particles. Figure 2a shows the SEAD pattern for the samples. The presence of diffuse rings overlaid with distinct spots is very evident. This is an indication of the presence of crystalline component to an otherwise amorphous material in the nano-fluid 1S1. Up-to three rings could be clearly indexed to the (111), (202) and (311) planes corresponding to the FCC 


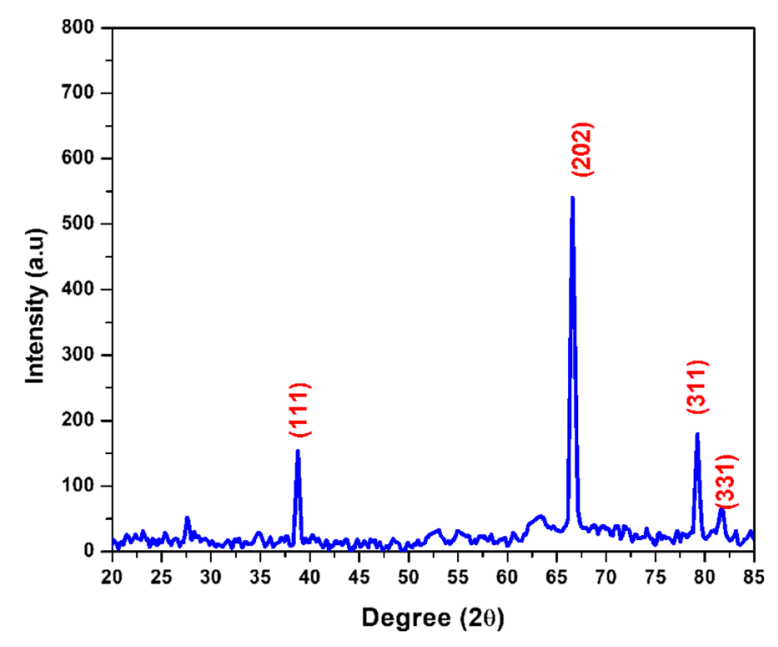

Fig. 1 X-ray diffraction data for a drop cast thin film grown using the Ag nano-particle

crystal structure of Ag. The inset in Fig. 2a shows the orthogonal lattice spacing measured from the SEAD pattern. The diffraction pattern in Fig. $2 b$ focuses on a single grain and shows the $\mathrm{d}$-spacing is of $\sim 0.26 \mathrm{~nm}$. Figure $2 \mathrm{c}$ shows spherical shape of the Ag-NPs obtained through the green route, i.e. reduction of $\mathrm{AgNO}_{3}$ by the contents of the leaf extract in the leaf broth. They nano-particles possess nicely faceted morphology as seen. There appears to be more or less homogenous distribution in size of the nano-particles. Inset in Fig. 2c shows the histogram depicting the average particle size distribution in the aqueous solution. Maximum number of Ag-NPs is found to be having a size in the range $\sim 25-30 \mathrm{~nm}$.

\section{FTIR analysis}

The results of FTIR analysis conducted on the sample 1S5 show different stretches of bonds as shown in Fig. 3 which could be used to identify various functional groups responsible for the bio-reduction of $\mathrm{Ag}^{+}$ions and capping and/or stabilization of the Ag nanoparticles. The FTIR spectra shows absorption bands at 3623, 2695, 2145, 1767, 1401 and $795 \mathrm{~cm}^{-1}$ indicating presence of capping agent with the nanoparticles. The broad absorption band at $3623 \mathrm{~cm}^{-1}$ corresponds to $\mathrm{O}-\mathrm{H}$ stretching vibration indicating the presence of amide. The band at $2695 \mathrm{~cm}^{-1}$ arising from $\mathrm{C}-\mathrm{H}$ stretching of aromatic compound were observed. The band at $1767 \mathrm{~cm}^{-1}$ corresponds to $\mathrm{C}-\mathrm{N}$ and $\mathrm{C}-\mathrm{C}$ stretching indicating the presence of proteins. The band at $1401 \mathrm{~cm}^{-1}$ could be assigned to the $\mathrm{N}-\mathrm{H}$ stretch vibration present in the amide linkages of the proteins. The band at $795 \mathrm{~cm}^{-1}$ was assigned to the $\mathrm{C}=\mathrm{CH}_{2}$ stretch vibrations.

\section{Inductively coupled mass spectrometry (ICP-MS) analysis} ICP-MS analysis was conducted on the sample 1S5 in order to quantify its concentration. Based on the results of the analysis the concentration of silver in the sample was found to be $33.81 \mathrm{mg} / \mathrm{L}$.

\section{Optical absorption studies}

The formation of the Ag-NPs was monitored by physical observation of change in color of the transparent $\mathrm{AgNO}_{3}$ ion solution which when mixed with the leaf extract turned orange-red. Metal nano-particles have free electrons, which gives Surface Plasmon Resonance (SPR) absorption band due to the combined vibration of electrons of metal nano-particles in resonance with light wave. The Time dependence of optical absorption of the prepared Ag nano-particles was studied using UVVIS spectroscopy. The spectra for sample 1S5 are given in Fig. 4 which showed maximum stability. The sample showed absorbance peak at $422.5 \mathrm{~nm}$ due to surface Plasmon resonance effect which confirms the formation of Ag nano-particles. The spectra were recorded at different time intervals from 2 to 67 days. The intensity of absorption band increases with time with slight shift in surface Plasmon resonance from 422.5 to $432.5 \mathrm{~nm}$.

A useful mathematical equation which relates diameter of the nano spheres to their surface plasmon resonance wavelength $\left(\lambda_{\mathrm{SPR}}\right)$ for silver particles is given by

$$
\lambda_{\text {spr }}=382.6+1.18 d_{a v}
$$

where $d_{a v}$ is the average diameter of particles [20]. Using relation 1 , we estimated the size of the Ag nano-particles. The size of the nano-particles was calculated to be $47 \mathrm{~nm}, 37 \mathrm{~nm}$ and $45 \mathrm{~nm}$ for the samples 1S1, 1S5 and $1 \mathrm{~S} 8$ respectively. The size of the Ag nano-particles for the samples $3 \mathrm{~S} 1$ and $3 \mathrm{~S} 5$ were found to be $38 \mathrm{~nm}$ and $46 \mathrm{~nm}$ respectively using the same relation.

\section{Photo-catalytic activity of samples 1S1, 1S5 and 3S1}

Among the different samples prepared the samples 1S1, 1S5 and 3S1 which exhibited greater stability were used for the photo degradation studies of Rhodamine $B$ dye solution of molarity $20 \mu \mathrm{mol} / \mathrm{L}$. Figure 5 shows the Time dependence of optical absorption for the dye solution mixed with the respective nano-fluids containing the suspended Ag nano-particles when exposed to direct sunlight. There is progressive decrease in intensity for the absorption peak with time. It is observed that the maximum absorption peak shifts towards the blue region with respect to time and its intensity becomes very low after $12 \mathrm{~h}$ of continuous solar irradiation for 1S5 and 3S1 samples. But for 1S1 sample the degradation is very small which may be due to its lowest absorption of light as evident from the optical absorption spectra. The 1S5 sample 

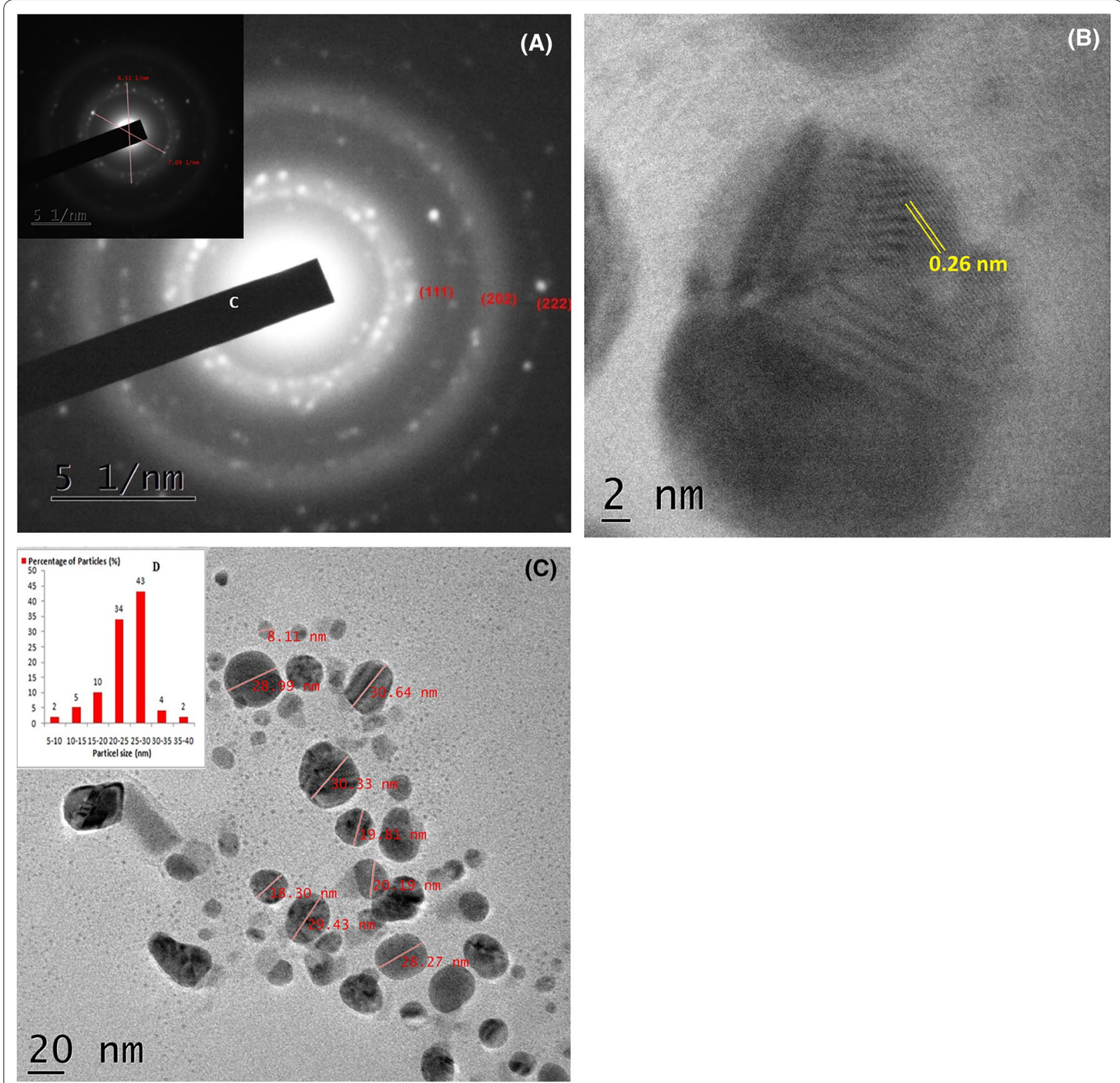

Fig. 2 a The SEAD pattern for sample 1S5: shows diffuse rings overlaid with distinct spots indicating the presence of crystalline component to an otherwise amorphous material. Inset in figure show the orthogonal lattice spacing. b TEM image for sample 1S5 showing a single grain with the $\mathrm{d}$-spacing of $0.26 \mathrm{~nm}$. c TEM image for sample $1 \mathrm{~S} 5$ showing the distribution in size of the formed Ag-NPs and inset is the histogram representing average particle size distribution in the aqueous solution

shows the highest degradation among the three samples, which may be due to its smaller particle size as evident from the SPR peak which is blue shifted to $\sim 422 \mathrm{~nm}$ relative to the other samples.

The kinetic studies of the RhB dye degradation process play an important role in assessing the efficiency and feasibility of treating dye from contaminated water and also assessing the photo catalytic capability of the studied catalyst. Therefore, the kinetic study of $\mathrm{RhB}$ dye degradation under direct sunlight has been discussed here. According to Langmuir-Hinshelwood (L-H) model, the rate expression at low initial concentration is given by

$$
r=-\frac{d C}{d t}=k_{a p p} C
$$




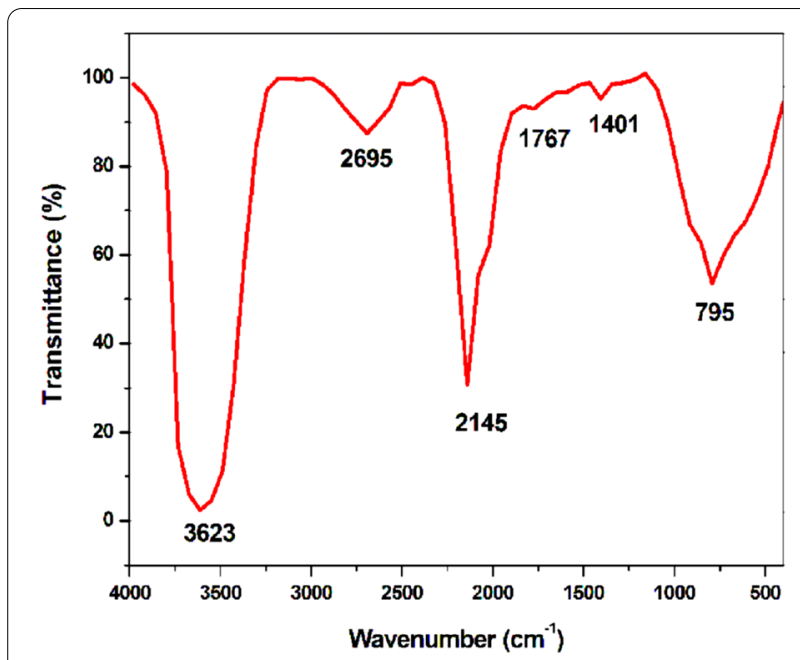

Fig. 3 FTIR spectra for the sample 1S5

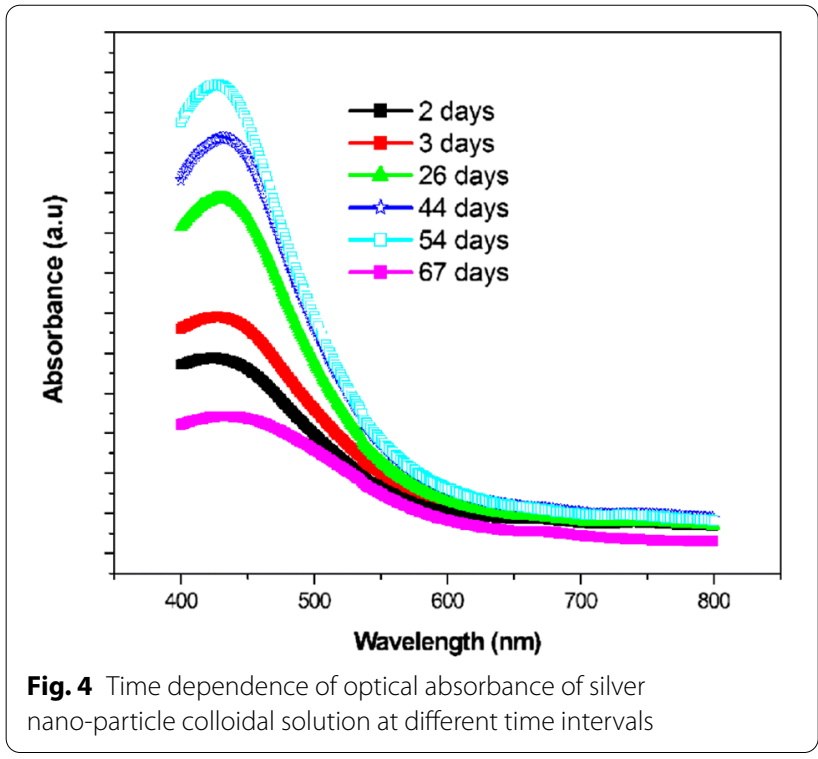

where $k_{\text {app }}$ is the apparent first order rate constant with $C=C_{0}$ at $t=0$ representing the initial concentration of the dye in the bulk after dark absorption and " $\mathrm{t}$ " is the reaction time. [21] We have used the absorption results of a concentration of $0.1 \mathrm{M} / \mathrm{L}$ of the RhB dye as a baseline for rate determination. Table 1 compares the first order rate constants obtained for the samples. Figure 6a represents the plot of $(\mathrm{C} / \mathrm{C} 0)$ versus time for the samples $1 \mathrm{~S} 1$, 1S5 and 3S1. It is evident from the plot that the sample 1S5 exhibits higher degradation efficacy relative to $3 \mathrm{~S} 1$ and 1S1. Figure $6 \mathrm{~b}$ shows the linear fit to the natural logarithmic plot of $(\mathrm{C} / \mathrm{Co})$ versus time for the samples.
Photo-catalytic activity of sample 1S5 for the degradation of RhB of different concentrations

Figure 7 represents the time dependent optical absorption spectra demonstrating the photo catalytic degradation of $\mathrm{RhB}$ dye at different $\mathrm{RhB}$ concentrations of: $10 \mu \mathrm{mol} / \mathrm{L}, 15 \mu \mathrm{mol} / \mathrm{L}, 20 \mu \mathrm{mol} / \mathrm{L}, 25 \mu \mathrm{mol} / \mathrm{L}$ and $30 \mu \mathrm{mol} / \mathrm{L}$ under direct sunlight illumination. The plots of $\ln \left(\mathrm{C}_{0} / \mathrm{C}\right)$ versus time for photo degradation at these concentrations under direct sunlight illumination are shown in Fig. 8a. The linear fit between $\ln \left(\mathrm{C}_{0} / \mathrm{C}\right)$ and irradiation time as shown in Fig. $8 \mathrm{~b}$ supports the conclusion that the degradation follows first-order kinetics. The values of regression coefficient $\left(R^{2}\right)$ of the experimental trials were more than 0.99 indicating that the degradation of $\mathrm{RhB}$ by the nano-particles followed an apparent-first-order kinetics. Our results indicate that the initial concentration of the dye plays a critical role in controlling the degradation rate. Table 2 shows the rate constant and $\mathrm{R}^{2}$ values obtained from the linear fit of the logarithmic plot of $\left(\mathrm{C}_{0} / \mathrm{C}\right)$ versus time for different $\mathrm{RhB}$ dye concentrations of in the presence of nanofluid sample 1S5 under direct sunlight.

Under dark conditions the RhB dye in the nano-fluid suspension did not undergo any degradation. When the mixture of the dye and the nano-fluid suspension was exposed to direct sunlight irradiation a photo-catalytic degradation pathway may have been activated. The photo-catalytic pathway can be summarized as follows: the localized surface Plasmon resonance (LSPR) of AgNPs can lead to very efficient absorption of light. The de-phasing of the resonant oscillation of the conduction electrons generate hot electrons [22].The energies of these hot electrons are $\sim 4 \mathrm{eV}$ for $\mathrm{Ag}$ nano-particles [23]. These hot electrons may be trapped by oxygen to form oxygen species.

$$
\mathrm{e}^{-}+\mathrm{O}_{2} \rightarrow \cdot \mathrm{O}_{2}^{-}
$$

The $\mathrm{Ag}+$ ion and the newly formed oxygen species further react with water to generate hydrogen peroxide anions (HO2") and increased number of hydroxyl radicals (" $\mathrm{OH})[23]$. The highly reactive oxidative species oxidize the $\mathrm{RhB}$ in aqueous solution to produce $\mathrm{CO}_{2}$, water and some simple mineral acids [28].

$$
\cdot \mathrm{O}_{2^{-}}+\mathrm{RhB} \rightarrow \mathrm{CO}_{2}+\mathrm{H}_{2} \mathrm{O}+\text { acids }
$$

A clear decrease in absorbance along with a shift in the position of the main absorbance peak is observed for all of the RhB solution in the presence of the nanofluids containing the Ag nano-particles. This is suggestive of a photo-degradation pathway which consists of an initial N-de-ethylation step [23]. There is an increase in photo-degradation rate with increasing $\mathrm{RhB}$ initial 


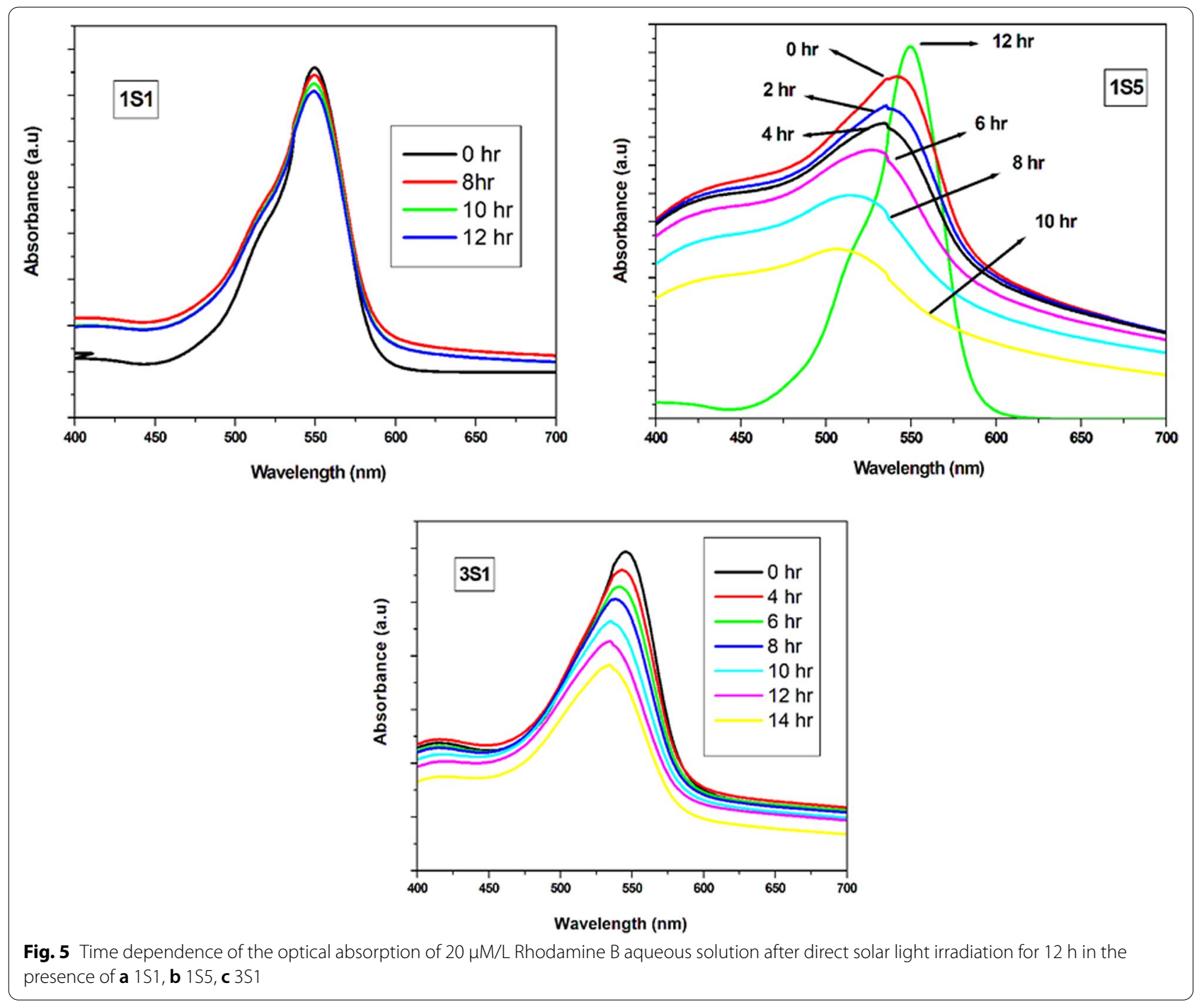

Table 1 Rate constant and $R^{2}$ values obtained from the linear fit of the logarithmic plot of $\left(C_{0} / C\right)$ versus time for different nanofluid samples used to degrade $20 \mu \mathrm{M} / \mathrm{L}$ Rhodamine B aqueous solution

\begin{tabular}{lll}
\hline Sample name & Rate constant $\mathbf{1 0}^{\mathbf{3}}\left(\mathbf{m i n}^{\mathbf{- 1}}\right)$ & $\mathbf{R}^{\mathbf{2}}$ \\
\hline 1S1 & 0.103 & 0.854 \\
1S5 & 0.94 & 0.933 \\
3S5 & 0.675 & 0.953 \\
\hline
\end{tabular}

concentration. This may be due to the increased photosensitization process with increase in concentration of dye. This process saturates when maximum number of dye molecules are adsorbed onto the Ag-NP surface.

In Fig. 9, a comparison of the photo-catalytic decay in terms of the decrease in peak absorbance of the $20 \mu \mathrm{mol} / \mathrm{L}$ dye solution mixed with sample 1S5 under direct sunlight illumination and under focused halogen light source is shown. It is apparent that under focused light the rate of dye decay is much faster. The rate constant for the degradation of $20 \mu \mathrm{mol} / \mathrm{L}$ concentration of dye solution was found to be $3.02 \times 10^{-3} \mathrm{~min}^{-1}$.

\section{Degradation of sulforhodamine B}

Figure 10 shows the optical absorbance of the sulforhodamine B dye which is centered at $550 \mathrm{~nm}$. Figure 10 also shows the time dependence of the optical absorbance of the dye solution mixed with the nano-fluid sample 1S5 containing the suspended Ag nano-particles kept in dark. The time dependence of the optical absorbance of the dye solution mixed with the nano-fluid sample $1 \mathrm{~S} 5$ after $1 \mathrm{~h}$ of exposure to direct sunlight is also represented in Fig. 10. It is evident that the nano-fluid causes absorbance at $\sim 550 \mathrm{~nm}$ of the sulforhodamine B dye to be quenched rapidly without exposure to sunlight. This 

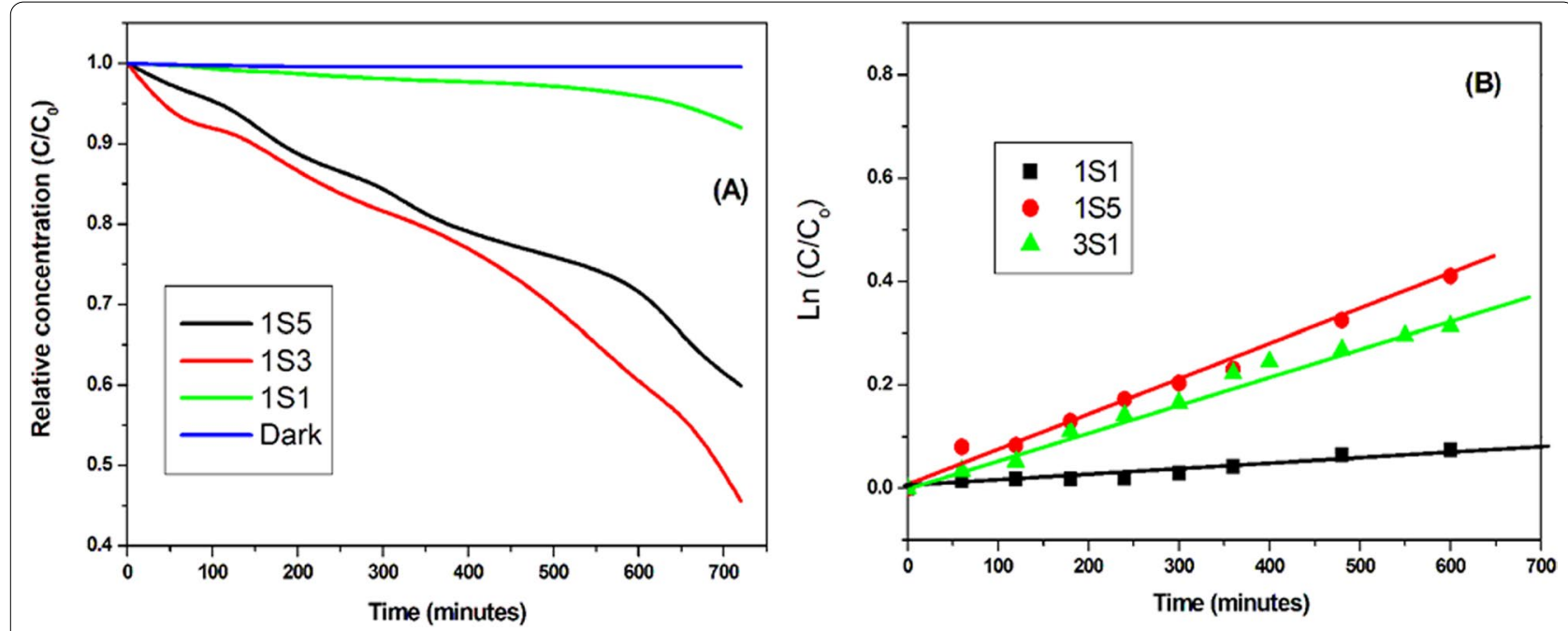

Fig. 6 A Plot of $(C / C 0)$ versus time for the samples $1 S 1,1 S 5$ and 3S1, B Plot of $L n\left(C_{0} / C\right)$ versus decay time for degradation of $20 \mu M / L$ Rhodamine $B$ aqueous solution in the presence of nano-fluid samples $1 \mathrm{S1}, 1 \mathrm{~S} 5$ and $3 \mathrm{S1}$
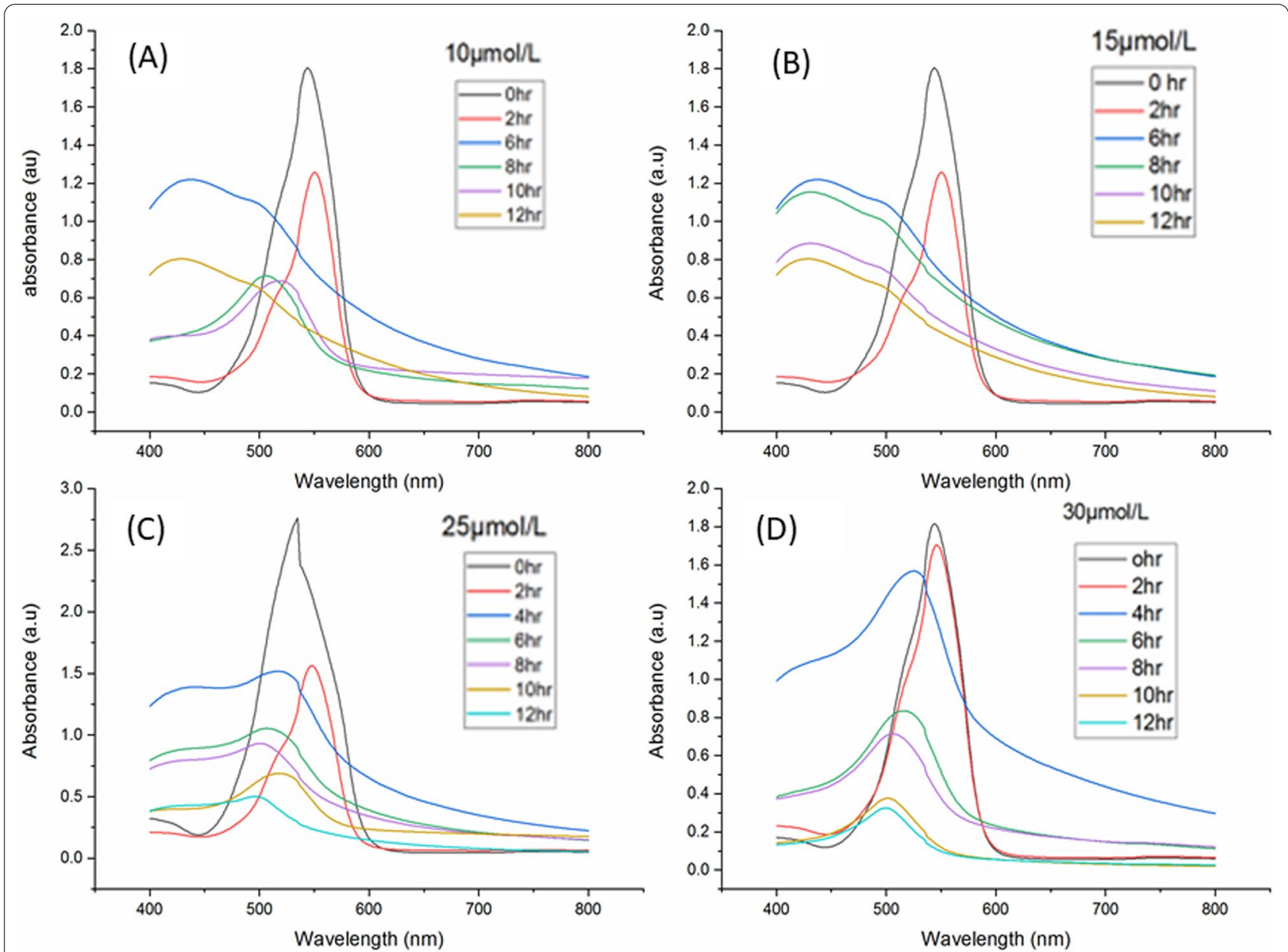

Fig. 7 Time dependence of optical absorption spectra of RhB of different concentrations- $10 \mu \mathrm{mol} / \mathrm{L}, 15 \mu \mathrm{mol} / \mathrm{L}, 20 \mu \mathrm{mol} / \mathrm{L}, 25 \mu \mathrm{mol} / \mathrm{L}$ and $30 \mathrm{\mu mol} / \mathrm{L}$ subjected to photo-catalytic degradation under direct sunlight by sample 1S5 

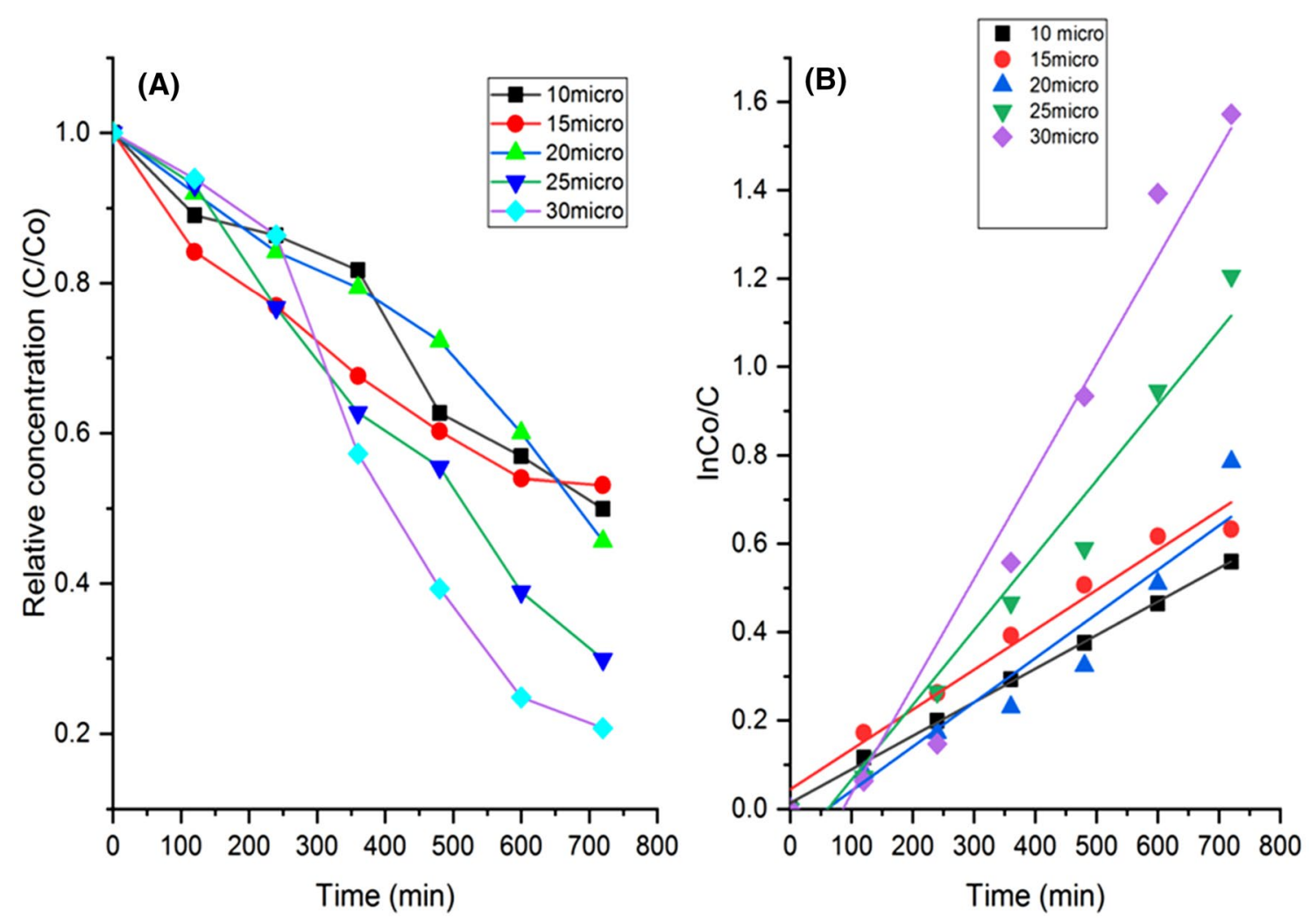

Fig. 8 A Plot of $\left(C / C_{0}\right)$ versus time for the samples $1 S 5$ and $\mathbf{B}$ Plot of $L n\left(C_{0} / C\right)$ versus decay time for different dye concentrations of in the presence of nano-fluid sample 1S5

Table 2 Rate constant and $R^{2}$ values obtained from the linear fit of the logarithmic plot of $\left(C_{0} / C\right)$ versus time for different $\mathrm{RhB}$ dye concentrations

\begin{tabular}{lll}
\hline RhB molarity & Rate constant*10 $\left.\mathbf{~} \mathbf{m i n}^{-\mathbf{1}}\right)$ & $\mathbf{R}^{\mathbf{2}}$ \\
\hline 10 & 0.7591 & 0.9983 \\
15 & 0.9024 & 0.97662 \\
20 & 0.94 & 0.933 \\
25 & 1.69 & 0.96808 \\
30 & 2.43 & 0.94828 \\
\hline
\end{tabular}

indicates that the sulforhodamine B dye can be removed by the without the use of sunlight by the Ag nano-particles synthesized by our process.

Figure 11 represents the catalytic degradation of different molar concentrations of the sulforhodamine $\mathrm{B}$ dye under dark condition by the Ag nano-particle colloidal solution. Our results show that the $0.1 \mu \mathrm{mol} / \mathrm{L}$ solution of the sulforhodamine B dye solution undergoes highest degradation relative to the other molar concentrations tested by us. This proves that lower

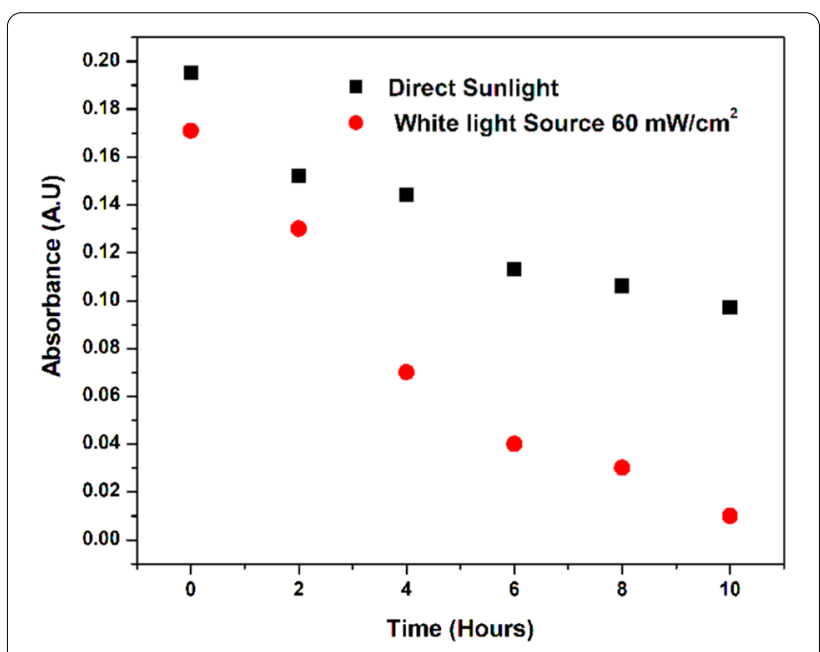

Fig. 9 Comparison of peak absorbance as a function of time for $20 \mathrm{\mu mol} / \mathrm{L}$ dye solution mixed with sample 1S5 under direct sunlight illumination and under white light source of intensity $60 \mathrm{~mW} / \mathrm{cm}^{2}$ 


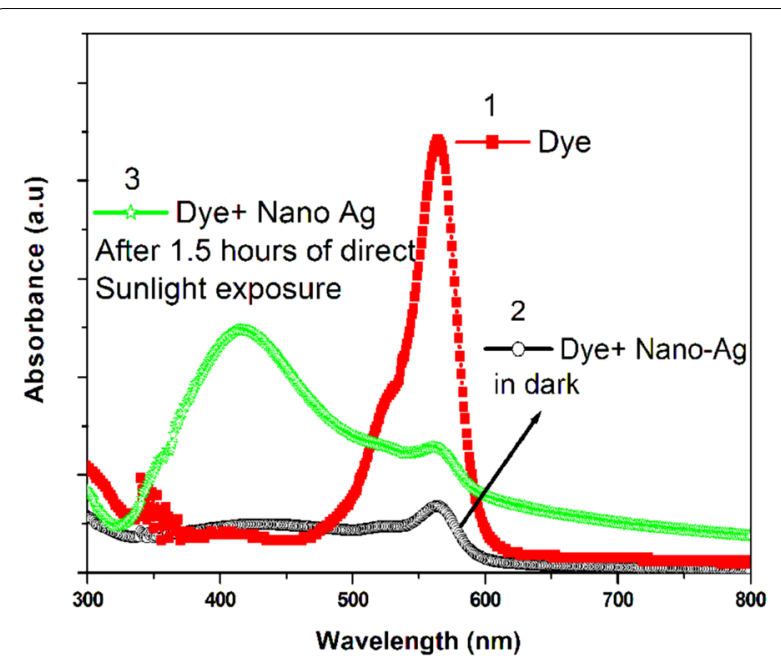

Fig. 10 Optical absorbance of (1) $1 \mu \mathrm{M} / \mathrm{L}$ sulforhodamine $\mathrm{B}$ dye aqueous solution, (2) mixture of sample 1S5 and $1 \mu \mathrm{M} / \mathrm{L}$ sulforhodamine $B$ dye aqueous solution immediately after mixing and (3) mixture of sample $1 \mathrm{~S} 5$ and $1 \mu \mathrm{M} / \mathrm{L}$ sulforhodamine $B$ dye aqueous solution after direct solar light irradiation for $1.5 \mathrm{~h}$

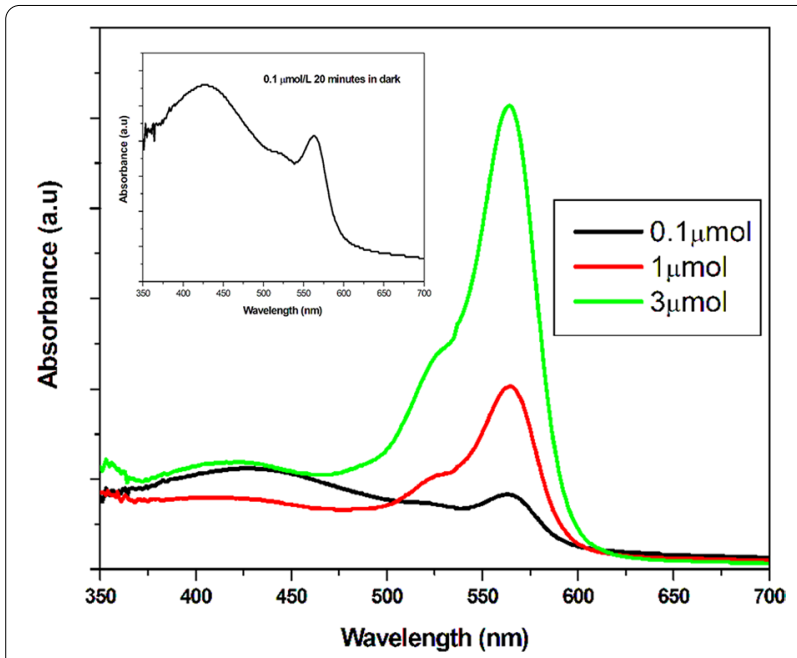

Fig. 11 Optical absorption spectra of mixture of silver nano-particle colloidal solution and $0.1 \mu \mathrm{mol} / \mathrm{L}, 1 \mu \mathrm{mol} / \mathrm{L}$ and $3 \mu \mathrm{mol} / \mathrm{L}$ sulforhodamine $B$ dye aqueous solution kept in dark for 5 min

concentration of the sulforhodamine $B$ dye molecules can be degraded in the dark by the Ag nano-particles synthesized using technique reported in this work.

On exposure to sunlight the absorbance peak of the mixture (dye + Ag nano-particle) is shifted to $\sim 417 \mathrm{~nm}$. This is suggestive of a photo-degradation pathway which consists of an initial N-de-ethylation step [23, 24]. The amount of sulforhodamine $B$ dye adsorbed
$\left(\mathrm{Q}_{\mathrm{Ad}}\right)$ by the Ag nano-particles at a time " $\mathrm{t}$ " may be estimated using the relation

$$
Q_{A d}=\left(\frac{C_{0}-C_{e}}{C}\right) \times V
$$

where $C_{0}$ and $C_{e}$ represent the concentration of the dye at the initial time $\mathrm{t}=0$ and at any measured time $\mathrm{t}$ respectively, $\mathrm{C}$ is the concentration the of the adsorbent and $\mathrm{V}$ is the volume of the solution in Litres [23]. During the studies on Rhodamine dye we had observed that the ratio between the molarity of $\mathrm{AgNO} 3$ and the volume of leaf extract played an arbitrating role in photo catalytic dye degradation efficacy. Hence to normalize this effect we have used constant volume "V" in relation (3) for our studies. It is observed that $93.67 \%$ of the initial dye concentration is removed after $3 \mathrm{~h}$ of exposure to direct sunlight showing a very good adsorption capacity of the $\mathrm{Ag}$ nano-particles for the removal of sulforhodamine B dye in aqueous media. Our results prove that the green synthezised Ag nano-particles can work as a catalyst both in the presence and absence of light for removal of the pollutant sulforhodamine B.

The Reactive Oxygen Species (ROS) study was undertaken to formulate the mechanism of the dye degradation in absence of light. Experiments by using Isopropanol as a quencher for ${ }^{*} \mathrm{OH}$ and 1,4-benzoquinone as a quencher for ${ }^{*} \mathrm{O}_{2}$ species were conducted. Figure 12 represents the optical absorbance for the mixture of dye with $\mathrm{Ag}$ nano-particle along with the respective quenching agents kept in dark. Our results indicate that a significant relationship exists between the presence of the ${ }^{*} \mathrm{O}_{2}$ species

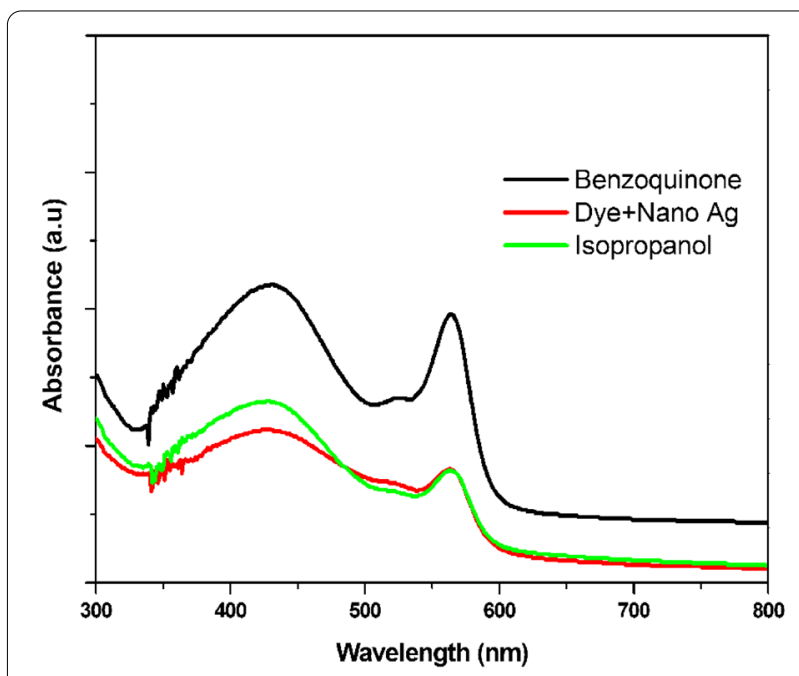

Fig. 12 Optical absorbance for the mixture of dye with Ag nano-particle kept in dark along with Isopropanol as a quencher for ${ }^{*} \mathrm{OH}$ and 1,4-benzoquinone as a quencher for ${ }^{*} \mathrm{O}_{2}$ species respectively 
quencher and the degradation efficiency. The * $\mathrm{OH}$ species quencher does not exhibit any significant contribution to the degradation of the sulforhodamine B dye in dark.

Figure 13 presents the FTIR spectra of the sulforhodamine $B$ dye before and after subjecting it to degradation in dark by the Ag nano-particles grown by us. A significant change in the IR bands located in the $3250 \mathrm{~cm}^{-1}$ range to $3750 \mathrm{~cm}^{-1}$ is evident. The results support our conclusion that the Ag nano-particles exhibit bleaching of the sulforhodamine B dye in the absence of light.

\section{Conclusions}

We have optimized a green process sequence using leaf extract of Ocimum tenuiflorum for the growth of Agnanoparticles which can yield average particle size of 25-30 $\mathrm{nm}$. Among the different nanoparticles grown by us the sample with an average particle size of 25-30 nm exhibited highest stability of over 2 months. Our findings suggest that the ratio between the molarity of AgNO3 and the volume of leaf extract does not have any role in controlling the size of the Ag nano-particles. The photo-catalytic activity of the green synthesized AgNPs was evaluated by degrading the Rhodamine $\mathrm{B}$ dye. We report that the ratio between the molarity of AgNO3 and the volume of leaf extract plays an arbitrating role in photo catalytic dye degradation efficacy. We tested the efficiency of degradation of RhB dye in the molarity range of $10 \mu \mathrm{mol} / \mathrm{L}$ to $30 \mu \mathrm{mol} / \mathrm{L}$ with the prepared Ag-NPs. The rate constant was found to increases from 10 to $30 \mu \mathrm{mol} / \mathrm{L}$, which may be due to the increased

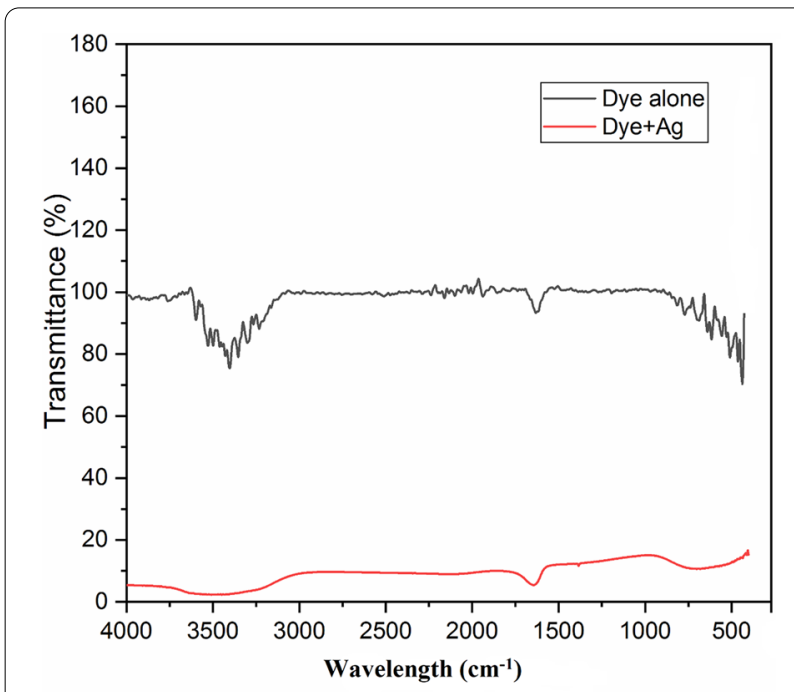

Fig. 13 FTIR spectra recorded for the sulforhodamine B dye aqueous solution before and after subjecting it to degradation by the Ag nano-particles photosensitization process with increase in concentration of dye. The kinetics of the dye degradation by the Ag-NPs, when studied under direct sunlight irradiation was found to follow first-order kinetics. Our work demonstrates that the carcinogenic dye sulforhodamine $B$ can be degraded by the green synthesized Ag nano-particle in the absence of light.

\section{Acknowledgements}

The authors would like to thank KSCSTE, Government of Kerala for facilities developed vide grant number KCSTE/433/2018-KSYSA which were made available for this research work.

\section{Authors' contributions}

RJ_Conceptualization, Methodology, Data Curation, Resources, Visualization, Writing - Review \& Editing, Supervision, Project administration, funding acquisition. AJ—Investigation, Formal analysis. VT—Supervision. All authors read and approved the final manuscript.

\section{Funding}

The work is funded by Directorate of Environment and Climate Change (DoECC), Government of Kerala vide Grant DoECC/E3/R\&D/1751/2017.

\section{Availability of data and materials}

All data and materials associated with the manuscript will be made available on request.

\section{Declarations}

\section{Competing interests}

The authors declare that there is no conflict of interest exists with the publication of this manuscript.

\section{Author details}

${ }^{1}$ Photovoltaic Research Laboratory, Department of Physics, University of Kerala, Karyavattom P.O, Thiruvananthapuram, India. ${ }^{2}$ Photovoltaic Research Laboratory, Department of Physics, Christian College, Chengannur, India.

Received: 27 May 2021 Accepted: 3 November 2021

Published online: 22 November 2021

\section{References}

1. Rochkind M, Pasternak S, Paz Y (2015) Using dyes for evaluating photocatalytic properties: a critical review. Molecules 20:88-110

2. Lu CH, Chen RY, Wu X, Fan MF, Liu YH, Le ZG, Jiang SJ, Song SQ (2016) Boron doped g-C3N4 with enhanced photocatalytic $\mathrm{UO} 22+$ reduction performance Appl. Surf Sci 360:1016-1022

3. U. Malavika Lakshmi Aruna Raj, Jishad A. Salam, R. Jayakrishnan, S. Priji, A. Gangaprasad, K.G. Gopchandran, V. Biju, (2021) DSSC using Wrightia tinctoria (Roxb.) R Br:: A trail, Materials Today: Proceedings https://doi.org/ 10.1016/j.matpr.2021.07.423

4. Hahn NT, Hoang S, Self JL, Mullins CB (2012) Spray pyrolysis deposition and photo-electrochemical properties of n-type BiOl nanoplatelet thin films. ACS Nano 6:7712-7722

5. C., Pelizzetti, E., Pichat, P., Sega, M., Vincenti, M. (1995) Formation of condensation products in advanced oxidation technologies: the photocatalytic degradation of dichlorophenols on TiO2. Minero Environ Sci Technol 29:2226-2234

6. Jose LM, Arun Raj RS, DSajan and Arun Aravind, (2021) Adsorption and photocatalytic activity of biosynthesised $\mathrm{ZnO}$ nanoparticles using Aloe Vera leaf extract. Nano Express 2:010039

7. Wang F, Zhang W, Tan X, Wang Z, Li Y, Li W (2019) Extract of Ginkgo biloba leaves mediated biosynthesis of catalytically active and recyclable silver nanoparticles. Colloid Surface A 563:31-36 
8. Li C, Ahmed T, Ma M, Edvinsson T, Zhu J (2013) A facile approach to ZnO/ $\mathrm{CdS}$ nanoarrays and their photocatalytic and photoelectrochemical properties. Appl Catal B Environ 138:175-183

9. Kapewangolo P, Hussein AA, Meyer D (2013) Inhibition of HIV-1 enzymes, antioxidant and anti-inflammatory activities of Plectranthus barbatus. J Ethnopharmacol. 149(1):184

10. Jayakrishnan R, Mathew TJ (2015) Time Time evolution of chlorophyll content in Ocimum tenuiflorum. Int J Appl Pure Sci Agric. 1:11

11. Martha Kandawa-Schulz and Debra Meyer (2017) Anti-HIV Activity of Ocimum labiatum Extract and Isolated Pheophytin-a. Petrina Kapewangolo Molecules 22(11):1763

12. Boxi SS, Paria S (2015) Visible light induced enhanced photocatalytic degradation of organic pollutants in aqueous media using Ag doped hollow TiO2 nanospheres. RSC Adv. 5:37657-37668

13. Jayakrishnan R, Abraham R, Koruthu DP, Manivarnan, (2015) Effect of Silver Plasmonic Layer on Cu2O/In2S3 Solar Cell. Int J Adv Appl Phys Res 2:15

14. Hoang S, Guo S, Hahn NT, Bard AJ, Mullins CB (2012) Visible light driven photoelectrochemical water oxidation on nitrogen-modified $\mathrm{TiO}_{2}$ nanowires. Nano Lett 12(1):26-32

15. Zhang Q, An Q, Luan X, Huang H, Li X, Meng Z, Tong W, Chen X, Chu PK, Zhang $Y$ (2015) Achieving significantly enhanced visible-light photocatalytic efficiency using a polyelectrolyte: the composites of exfoliated titania nanosheets, graphene, and poly(diallyl-dimethyl-ammonium chloride). Nanoscale 7:14002-14009

16. Brahmachari G, Sarkar S, Ghosh R, Barman S, Mandal NC et al (2014) Sunlight-induced rapid and efficient biogenic synthesis of silver nanoparticles using aqueous leaf extract of Ocimum sanctum Linn. with enhanced antibacterial activity. Org Med Chem Lett 4:18

17. Tailor G, Yadav BL, Chaudhary J, Joshi M, Suvalka C (2020) Green synthesis of silver nanoparticles using Ocimum canum and their anti-bacterial activity. Biochem Biophys Rep. 24:100848
18. Mavaei Mavaei M, Chahardoli A, Shokoohinia Y, Khoshroo A, Fattahi A (2020) One-step synthesized silver nanoparticles using isoimperatorin: evaluation of photocatalytic, and electrochemical activities. Sci Rep 10:1762

19. Fierascu RC, Ortan A, Avramescu SM, Fierascu I (2019) Phyto-nanocatalysts: green synthesis, characterization, and applications. Molecules 24:3418

20. Najmeh Aboutorabi S, Nasiriboroumand M, Mohammadi P, Sheibani H, Barani H (2018) Biosynthesis of silver nanoparticles using safflower flower: structural characterization, and its antibacterial activity on applied wool fabric. J Inorg Organomet Polym Mater 28:2525-2532

21. Alneyadi AH, Shah I, AbuQamar SF, Ashraf SS (2017) Differential degradation and detoxification of an aromatic pollutant by two different peroxidases. Biomolecules 7(1):31

22. Guangming Liu and Jincai Zhao (2000) Photocatalytic degradation of dye sulforhodamine B: a comparative study of photocatalysis with photosensitization New. J Chem 24:411

23. Raji R, Gopchandran KG (2018) Fast photocatalytic degradation of sulforhodamine B using ZnO: Cu nanorods. J Phys Chem Solids 113:39

24. Fangyan-Fen H-P, Liude-Fu HY, Wei G, Johnson D (2007) Photocatalytic degradation of the dye sulforhodamine-B: a comparative study of different light sources. J Environ Sci 19(1):97

25. Abuzalat O, Tantawy H, Abdlaty R, Elfiky M, Barakaa A (2021) Advances of the highly efficient and stable visible light active photocatalyst $\mathrm{Zr}$ (iv)-phthalate coordination polymer for the degradation of organic contaminants in water. Dalton Trans 50:8600-8611

\section{Publisher's Note}

Springer Nature remains neutral with regard to jurisdictional claims in published maps and institutional affiliations.

\section{Submit your manuscript to a SpringerOpen ${ }^{\circ}$ journal and benefit from:}

- Convenient online submission

- Rigorous peer review

- Open access: articles freely available online

- High visibility within the field

- Retaining the copyright to your article

Submit your next manuscript at $\boldsymbol{\nabla}$ springeropen.com 